\title{
Plasma visfatin response to the intensity of exercise and training in race-horses
}

\author{
Witold Kędzierski ', Iwona Janczarek², Izabela Wilk², Magdalena Staniszewska ${ }^{3,4}$, and Sylwester Kowalik ${ }^{5}$ \\ 1 Department of Biochemistry, University of Life Sciences in Lublin, Lublin, Poland \\ 2 Department of Horse Breeding and Use, University of Life Sciences in Lublin, Lublin, Poland \\ 3 Centre for Interdisciplinary Research, The John Paul II Catholic University of Lublin, Lublin, Poland \\ ${ }^{4}$ Department of Immunology of Infectious Diseases, Polish Academy of Sciences, Wrocław, Poland \\ ${ }^{5}$ Department of Animal Physiology, University of Life Sciences in Lublin, Lublin, Poland
}

\begin{abstract}
Summary: The regulation of visfatin release depends on physical activity, as shown in humans and laboratory animals. In this study, we aimed to test the hypothesis that physical training and/or exercise influence the plasma visfatin concentration in race-horses. A group of 22 young purebred Arabian horses submitted to race training of various intensities was studied. Twelve horses were submitted to standard race training, including gallops on a track at a speed of $6-12 \mathrm{~m} / \mathrm{s}$ for a distance of $600-1200 \mathrm{~m}$, six days a week (ST group). The other ten horses underwent standard training alternating with low intensity exercise sessions consisting of alternating walking, trotting and cantering at a maximum speed of $6 \mathrm{~m} / \mathrm{s}$, lasting about $30 \mathrm{~min}$; these were performed every second day of the week (LT group). Blood samples were collected three times during the training season: in the middle of May, July, and September. On each day of data collection, three jugular blood samples were collected, i.e. at rest, immediately after the end of the exercise session, and 30 min after the end of the exercise period. Blood plasma lactic acid (LA) concentration was determined immediately after the end of exercise. Plasma visfatin concentration was determined in samples collected at rest and 30 min after the end of exercise using ELISA. In the ST group, the plasma visfatin concentration decreased in September compared to May measurements. No significant correlations were found between post-exercise LA and visfatin values. In conclusion, plasma visfatin concentration in horses may decrease depending on the method of training. The short-term, intensive exercise performed in race training had no impact on the plasma visfatin concentration in young purebred Arabian horses at 30 min post-exercise.
\end{abstract}

Keywords: exercise, race-horse, lactic acid, training, visfatin

Citation: Kędzierski W., Janczarek I., Wilk I., Staniszewska M., Kowalik S. (2018) Plasma visfatin response to the intensity of exercise and training in race-horses. Pferdeheilkunde 34, 525-530; DOI 10.21836/PEM20180603

Correspondence: Witold Kędzierski, PhD, Department of Biochemistry, University of Life Sciences in Lublin, Akademicka 12, 20-033 Lublin, Poland; witold.kedzierski@up.lublin.pl

\section{Introduction}

Visfatin, also known as pre-B-cell-colony-enhancing factor 1 (PBEF1) or nicotinamide phosphoribosyltransferase (Nampt), is an enzyme that participates in nicotinamide metabolism. Visfatin is highly expressed in visceral fat and its plasma level increases mainly during the development of obesity (Fukuhara et al. 2005). It has been identified as a multifunctional adipocytokine present in the bloodstream. It is known that in mammals, visfatin plays an endocrine, autocrine, as well as a paracrine role (Adeghate 2008). This protein promotes, inter alia, the production of inflammatory cytokines, corticosterone release and vascular smooth muscle cell maturation (Cielichowski et al. 2018, Wu et al. 2018). Visfatin, together with leptin, regulates thermogenesis and the uncoupling protein synthesis in brown adipose tissue (Dimitriadis et al. 2018). Of particular importance, visfatin activates insulin receptors and has insulin-mimetic effects, improving insulin sensitivity and lowering the plasma glucose level (Fukuhara et al. 2005). Some studies demonstrated a tendency for daily fluctuations in plasma visfatin levels in mammals; they reported higher values of visfatin in the evening than in the morning, and an increase after a meal following 12-hour starvation (Ando et al. 2005, Bilski et al. 2016).

There is clear evidence that an active lifestyle decreases plasma or salivary visfatin concentrations (Aggeloussi et al. 2012, Roupas et al. 2012, Rudwill et al. 2013). In rats, six-weeks of swimming exercise down-regulated visfatin levels in adipose tissue (Gao et al. 2014). In humans, an exercise training programme lasting at least 12 weeks significantly decreased plasma visfatin concentration (Choi et al. 2007, Haus et al. 2009). However, the post-training decrease in plasma visfatin concentration was closely related to the body fat mass lost in overweight participants (Lee et al. 2010, Jürimäe et al. 2011, Seo et al. 2011 ). Thus, physical training led to a decrease in plasma visfatin concentration in the studied subjects. On the other hand, single bouts of exercise either increased (Frydelund-Larsen et al. 2007, Ghanbari-Niaki et al. 2010, Plinta et al. 2012) or decreased visfatin release from adipose tissue in humans (Jürimäe et al. 2009).

These ambiguous results lead to further questions about the physiological relevance of visfatin, especially in other mammals, including horses. To the best of the authors' knowledge, no studies exist regarding visfatin regulation in horses. These domestic animals are generally used for different kinds of work and are routinely submitted to a long-lasting training regimen and extremely difficult exercise tests. The races, among other activities, require the most intensive exercise, however, visfatin in race-horses has not been thoroughly studied.

Thus, other than obesity, the main factors influencing plasma visfatin concentration in mammals are training and, probably, exercise. Therefore, the present study was designed to test the 
hypothesis that physical training and exercise of varying intensities alter the plasma concentration of visfatin in race-horses.

\section{Materials and methods}

Horses

The study was performed between May and September during one training season. A total of 22 purebred Arabian horses aged three to four years were assessed during their race training. Initially, the number of horses included in the study was larger, however, some horses were later excluded for reasons beyond the authors' control (e.g. a break in training due to injuries or infections, an owner's decision to move a horse). The investigated horses were trained and competed in official races on the Słu ewiec Horse Race Track (Warsaw, Poland). They completed their routine training and competed in official races during the whole race season. The studied horses were randomly divided into two groups according to the intensity of their training.

Twelve horses (3 three-year-old colts, 3 three-year-old fillies, 3 four-year-old colts and 3 four-year-old mares) were trained in a standard manner (ST group). They were exercised six days a week in a similar way. The training sessions were performed for about one hour a day. The riders rode the horses at a walk and trot for approximately 10 min as a warm-up exercise, then the horses cantered or galloped on a sand track at a speed of $6-12 \mathrm{~m} / \mathrm{s}$, covering a distance of $600-1200 \mathrm{~m}$. The speed and duration were individually adapted to each horse's performance level by the trainer. After exercise, the horses were cooled down on an automatic horse walker for $30 \mathrm{~min}$.

Ten horses ( 2 three-year-old colts, 2 four-year-old colts, 3 three-year-old fillies and 3 four-year-old mares) underwent standard training alternating with low intensity exercise sessions (LT group). Namely, three days a week (Mondays, Wednesdays and Fridays), these horses completed standard exercise sessions described as above, but on the other days of the week (Tuesdays, Thursdays and Saturdays), they had low intensity sessions which lasted at least 1.5 hours and included a warm-up walk (about $10 \mathrm{~min}$ ), alternating walking, trotting and cantering (at a maximum rate of $6 \mathrm{~m} / \mathrm{s}$ ) in a cohort (approximately $30 \mathrm{~min}$ ), and then walking toward the stable (about $10 \mathrm{~min}$ ). The horses were then cooled down on an automatic horse walker for $30 \mathrm{~min}$.

The horses from both studied groups began regular training in early April, and started to compete in official races at least once a month starting at the end of May. All studied horses were treated and fed in the same manner characteristic for their use in races. The colts and females were kept in separate stables within a box stall measuring $4 \mathrm{~m} \times 4 \mathrm{~m}$ and lined with straw bedding. During the study, each horse received an individual ration of hay, oats and concentrate according to their body condition and workload. The daily feed dose was split into three feedings provided at $6 \mathrm{am}, 12 \mathrm{pm}$ and $6 \mathrm{pm}$. The feeding regimen ( $\mathrm{kg} /$ horse) for three-year-old horses in July was as follows: $5.5 \mathrm{~kg}$ oats, $6.0 \mathrm{~kg}$ meadow hay, and $0.8 \mathrm{~kg}$ concentrate. A mineral salt block and fresh water were provided ad libitum.
For each horse, the body condition score (BCS) was always determined by the same, experienced veterinarian. The method is based on the visual and palpable evaluation of fat cover over set points of a horse's body. The rating system devised by Henneke et al. (1983) was used, with scores ranging from 1 to 9. All studied horses took part in official races until the end of the race season. The official published handicap value for each horse was divided by the mean handicap for all similar-aged horses that had started on the race track throughout the whole season (relative handicap).

\section{Blood sampling and analysis}

All horses were studied during morning exercise sessions. Blood samples were collected three times at two-month intervals, i.e. in the middle of May, July, and September. In May, all horses galloped at a speed of $6-8 \mathrm{~m} / \mathrm{s}$, covering a distance of $1200 \mathrm{~m}$. In July and September, some horses galloped at a low speed (about $6 \mathrm{~m} / \mathrm{s}$ ), some others at a medium speed (about $9 \mathrm{~m} / \mathrm{s}$ ), and others at a high speed (exceeding $12 \mathrm{~m} / \mathrm{s}$ ), according to the trainer's rules. The speed of each horse was monitored using Polar RS800CX telemeters equipped with GPS sensors (Polar OY, Kempele, Finland).

On each day of data collection, three jugular blood samples were collected: 1) at rest, immediately before the exercise session; 2) immediately after the end of exercise; 3) $30 \mathrm{~min}$ after the end of the exercise period. Blood samples were collected into tubes containing tri-potassium EDTA and were immediately cooled in a water bath with a temperature of $+4^{\circ} \mathrm{C}$, centrifuged, aliquoted and stored frozen at $-70^{\circ} \mathrm{C}$ until analysis.

Plasma visfatin concentration was determined in samples collected at rest and 30 min after the end of exercise, using a horse visfatin ELISA kit (Wuhan Fine Biological Technology Ltd., Hubei, China). The sensitivity of the assay was $0.94 \mathrm{ng} / \mathrm{ml}$, and the range was from 1.56 to $100 \mathrm{ng} / \mathrm{ml}$. Absorbance was measured by a Multiskan reader (Labsystem, Helsinki, Finland) using GENESIS V 3.00 software. The intraand inter-assay for data determined in the laboratory amounted to $6 \%$ and $8 \%$, respectively; values were expressed in $\mathrm{ng} / \mathrm{ml}$. To evaluate the relative intensity of exercise, the blood plasma lactic acid (LA) concentration was determined in samples collected immediately after the end of exercise. Plasma LA concentrations were measured using the colorimetric method and a Dr. Lange portable analyser (Dr. Lange Laboratory System LP450, Germany).

\section{Statistical analysis}

Statistical analysis was performed using a multifactorial ANOVA assay (GLM, SAS software 9.3) to test the influence of the time of blood sampling (May, July, September), activity (at rest, $30 \mathrm{~min}$ after the exercise period), and training intensity (ST and LT groups). Data were checked for normality of distribution using Shapiro-Wilk, Kolmogorov-Smirnov, and Anderson-Darling tests; the tests did not reject the normal distribution hypothesis. Post hoc multiple comparisons were made using Tukey's test. The relative handicap values in ST and LT groups were compared using a Student's t-test. The 
Pearson correlation coefficient was calculated to compare plasma visfatin values obtained at rest with BCSs, as well as exercise-induced changes in plasma visfatin concentrations with post-exercise LA values. Statistical significance was accepted at $P<0.05$. The results are presented as means \pm standard deviations (SD).

\section{Results}

Plasma visfatin concentrations measured at rest are shown in Table 1. The most important, statistically significant differences were observed in the ST group, where the mean value of visfatin decreased in September as compared to May measurements. The mean concentrations of the studied adiponectin in plasma collected at rest and after exercise did not differ significantly (data not shown). Plasma LA concentrations in studied horses ranged from $0.7 \mathrm{mmol} / \mathrm{l}$ to $22.5 \mathrm{mmol} / \mathrm{l}$, depending on the speed of gallop. Data obtained in the individual months of the study are presented in Table 2 . The mean post-exercise LA concentration reached $7.50 \pm 6.48 \mathrm{mmol} / \mathrm{l}$ (median $=5.01 \mathrm{mmol} / \mathrm{l})$. The correlation coefficient for LA and differences between plasma visfatin concentrations determined after exercise and at rest was 0.08 , and did not reach the level of statistical significance. The mean BCS values in studied horses tended to decrease gradually during the study: $4.9 \pm 0.38$ in May, $4.5 \pm 0.30$ in July, and $4.3 \pm 0.28$ in September $(P=0.056)$; $B C S$ did not differ significantly between the studied groups. There was no significant correlation between BCS and plasma visfatin concentrations determined at rest in the studied horses.

The mean estimated relative handicap for the LT group was significantly higher than for the ST group (Table 2).

\section{Discussion}

The results of this study indicate that training may decrease the plasma visfatin concentration in purebred Arabian horses training for races. The decrease in the adipokine level was evident in horses in the standard race training programme only, in the period of time from May to September, during one training season. However, no similar decrease was found in the horses that trained less intensively. The studied horses were trained using two strategies because trainers constantly try new methodologies to improve the effectiveness of the training process (Szarska et al. 2014, Ringmark et al. 2017). It can be concluded that intense race training lasting at least six months may lead to a decrease in plasma visfatin concentration. It seems that this is a phenomenon that is characteristic for mammals. A training-induced drop in plasma visfatin concentration was

Table 1 Plasma visfatin concentration determined at rest in purebred Arabian race horses ( $\mathrm{ng} / \mathrm{ml}$; means \pm standard deviations)

\begin{tabular}{lcc}
\hline Time of sample collection & ST group & LT group \\
\hline May & $24.3 \pm 2.98^{a}$ & $23.6 \pm 2.71^{a}$ \\
July & $21.4 \pm 2.93^{\mathrm{ab}}$ & $22.1 \pm 3.69^{a}$ \\
September & $19.9 \pm 3.03^{\mathrm{b}}$ & $23.0 \pm 3.86^{a}$ \\
\hline
\end{tabular}

ST group - horses trained in a standard manner; LT group - horses trained less intensively $a, b$ - means in columns marked with the same letters do not differ significantly at $P<0.05$, according to Tukey's test previously described in humans (Choi et al. 2007, Haus et al. 2009, Aggeloussi et al. 2012, Roupas et al. 2012, Rudwill et al. 2013), as well as in rats (Gao et al. 2014). A drop in visfatin level caused by physical training can be the result of decreased sensitivity to corticosteroids. Corticosteroids stimulate visfatin synthesis in adipocytes (MacLaren et al. 2007), however, glucocorticoid receptor synthesis is downregulated during training (Bonifazi et al. 2009, Campbell et al. 2009), as the tissue's response to long-lasting cortisol elevation induced by training (Kędzierski 2014). It is also possible that a decrease in visfatin is a result of systematically repeated exposure to free fatty acids. Namely, an increase in the lipolysis rate with daily exercise leads to a higher concentration of free fatty acids in plasma (Kędzierski 2014) and downregulates the visfatin gene expression in adipocytes (Wen et al. 2006).

In the present study, no correlation was found between BCS values and plasma visfatin concentrations. This is in contrast with other studies showing correlations between visfatin and overall adiposity in humans (Jürimäe et al. 2011, Aggeloussi et al. 2012). In fact, these studies compared overweight, physically inactive individuals with lean, physically active ones. The horses in the present study had similar BCSs, ages, and performance levels. Individual differences in BCS and plasma visfatin concentrations were rather low. We observed a similar phenomenon for leptin, another adipokine produced by adipose tissue (Kędzierski 2014, 2016b). In general, the level of plasma leptin reflects the body fat stores (Gentry et al. 2002, Kearns et al. 2006), however, some horses have high or low resting leptin levels regardless of their body fat mass (Cartmill et al. 2003, Suagee et al. 2013). Thus, the plasma leptin concentration did not correlate with BCS in groups of horses of similar body condition and race performance (Gordon and McKeever 2005, Kędzierski 2016 a).

The lack of influence of performed exercise on plasma visfatin concentration in studied horses is also worth noting. Regardless of the intensity of the exercise, there were no changes in the plasma concentration of visfatin when assessed $30 \mathrm{~min}$ after the end of exercise and at rest. However, exercise was not standardised; only the plasma LA concentration determined immediately after the end of an exercise session was used to evaluate the relative intensity of the exercise. It is possible than other undefined factors, like training phase or horse performance, could influence the release of visfatin during and after exercise. In some reports, exercise induced an increase in this adipokine production in humans (Frydelund-Larsen et al. 2007, Ghanbari-Niaki et al. 2010). However, other researchers did not find exercise-induced changes in visfatin values

Table 2 Plasma lactic acid concentration (LA, mmol/I) determined immediately after the end of the exercise, and relative handicap in studied horses (means \pm standard deviations)

\begin{tabular}{|c|c|c|}
\hline Time of sample collection & ST group & LT group \\
\hline May & $5.58 \pm 2.05$ & $4.62 \pm 1.95$ \\
\hline July & $8.28 \pm 7.09$ & $7.74 \pm 5.19$ \\
\hline September & $5.30 \pm 3.43$ & $10.1 \pm 6.58$ \\
\hline Handicap & $0.88 \pm 0.09^{x}$ & $1.01 \pm 0.11^{y}$ \\
\hline \multicolumn{3}{|c|}{$\begin{array}{l}\text { ST group - horses trained in a standard manner; LT group - horses trained les } \\
\text { intensively } x, y \text { - means in rows marked with different letters differ significantly a } \\
P<0.05 \text {, according to Student's t-test; for LA, - no statistically significant } \\
\text { differences were found according to Tukey's test. }\end{array}$} \\
\hline
\end{tabular}


(Roupas et al. 2013), or simply found an exercise-induced drop in this adipokine (Jürimäe et al. 2009, Roupas et al. 2012, Bilski et al. 2016). These reported discrepancies in visfatin responses to exercise could be a partial result of variations in the type of studied exercises: anaerobic versus aerobic, intensive short-term versus endurance exercise. The intensity and duration of exercise can affect the response of the organism and change multiple biochemical parameters, hormones or cytokines. Once again, by analogy, plasma leptin concentration increased after exercise, lasting at least $45 \mathrm{~min}$, but only in very young or untrained horses (Gordon et al. 2006, Kędzierski and Kapica 2008, Kędzierski 2016b). No exercise-induced changes in plasma leptin concentration were found in response to training sessions typical for galloping race horses (Kędzierski 2014, Kędzierski and Cywińska 2014). Similarly to leptin, plasma visfatin concentration was probably not affected by the short-time exercise used in race training. It is also probable that the $30 \mathrm{~min}$ post-exercise rest implemented in the study was too short to achieve any changes in visfatin synthesis and release. Finally, we found that the horses that submitted to standard race training achieved worse results in official races than horses from the less intensively trained group. Thus, if less intense training, which was applied to the LT group, was sufficient to achieve the handicap on a medium level, it can be assumed that horses in the ST group were overtrained. However, the genetic component specifying the performance of the individual horse cannot be excluded.

To summarise, this is the first study that shows a training-induced decrease in plasma visfatin concentration in horses. In general, training should lead to improving the efficiency of exercise and, inter alia, to an increase in the oxidation rate of lipids, as well as a decrease in glucose utilisation and LA production in exercised muscles. Therefore, the importance of glucose as a source of energy decreases with time spent training. Thus, taking into account the fact that visfatin improves tissue sensitivity to insulin and simultaneously decreases the glucose level in the blood, a drop in plasma visfatin concentration in intensively trained horses could be a marker for the horses' performance, indicating over-training. Further research is needed to test the changes in exercise-induced visfatin kinetics. This study is limited to purebred Arabian race-horses and therefore, these findings might not apply to other horses exercised in a different way.

\section{Conclusions}

The intensity of short-term exercise has no impact on plasma visfatin concentration as determined in horses at 30 min postexercise. Nevertheless, plasma visfatin concentration in horses may decrease under the influence of intensive training. Thus, visfatin is a measurable adipokine that should be further investigated in horses to test the hypothesis that it can be a new, usable parameter to indicate the performance level of trained horses.

\section{Animal Welfare statement}

The study was performed in accordance with the protocol approved by the Local Ethic Review Committee for animal experiments in Lublin (reference number 45/2017).

\section{References}

Adeghate E. (2008) Visfatin: structure, function and relation to diabetes mellitus and other dysfunctions. Curr. Med. Chem. 15, $1851-1862$

Aggeloussi S., Theodorou A. A., Paschalis V., Nikolaidis M. G., Fatouros I. G., Owolabi E. O., Kouretas D., Koutedakis Y., Jamurtas A. Z. (2012) Adipocytokine levels in children: effect of fatness and training. Pediatr. Exerc. Sci. 24, 461-471

Ando H., Yanagihara H., Hayashi Y., Obi Y, Tsuruoka S, Takamura T, Kaneko S., Fujimura A. (2005) Rhytmic messenger ribonucleic acid expression of clock genes and adipocytokines in mouse visceral adipose tissue. Endocrinology 126, 5631-5636; DOI 10.1210/en.2005-0771

Bilski J., Jaworek J., Pokorski J., Nitecki J., Nitecka E., Pokorska J., Mazur-Bialy A., Szklarczyk J. (2016) Effects of time of day and the Wingate test on appetite perceptions, food intake and plasma levels of adipokines. J. Physiol. Pharmacol. 67, 667-676

Bonifazi M., Mencarelli M., Fedele V., Ceccarelli I., Pecorelli A., Grasso G., Aloisi A. M. Muscettola M. (2009) Glucocorticoid receptor mRNA expression in peripheral blood mononuclear cells in high trained compared to low trained athletes and untrained subjects. J. Endocrinol. Invest. 32, 816-820; DOI 10.3275/6428

Campbell J. E., Fediuc S., Hawke T. J., Riddell M. C. (2009) Endurance exercise training increases adipose tissue glucocorticoid exposure: adaptations that facilitate lipolysis. Metabolism 58, 651-660; DOI 10.1016/i.metabol.2009.01.002

Cartmill J. A., Thompson Jr D. L., Storer W. A., Gentry L. R., Huff N. $K$. (2003) Endocrine responses in mares and geldings with high body condition scores grouped by high vs. low resting leptin concentrations. J. Anim. Sci. 81, 2311-2321; DOI 10.2527/2003. $8192311 \mathrm{x}$

Choi K. M., Kim J. H., Cho G. J., Baik S. H., Park H. S., Kim S. M. (2007) Effect of exercise training on plasma visfatin and eotaxin levels. Eur. J. Endocrinol. 157, 437-442

Cielichowski P., Jopek K., Milecka P., Szyszka M., Tyczewska M., Malendowicz L. K., Rucinski M. (2018) Nicotinamid phosphoribosyltransferase and the hypothalamic-pituitary-adrenal axis of the rat. Mol. Med. Rep. 17, 6163-6173; DOI 10.3892/mmr.2018. 8569

Dimitriadis G. K., Adva R., Tan B. K., Jones T. A., Menon V. S., Ramanjaneya M., Kaltsas G., Miras A. D., Randeva H. S. (2018) Effects of visfatin brown adipose tissue energy regulation using T37i cells. Cytokine S1043-4666; DOI 10.1016/i.cyto.2018.07.013

Frydelund-Larsen L., Akerstrom T., Nielsen S., Keller P., Keller C., Pedersen B. K. (2007) Visfatin mRNA expression in human subcutaneous adipose tissue is regulated by exercise. Am. J. Physiol. Endocrinol. Metab. 292, E24-E31

Fukuhara A., Matsuda M., Nishizawa M., Segawa K., Tanaka M., Kishimoto K., Matsuki Y., Murakami M., Ichisaka T., Murakami H., Watanabe E., Takagi T., Akiyoshi M., Ohtsubo T., Kihara S., Yamashita S., Makishima M., Funahashi T., Yamanaka S., Hiramatsu R., Matsuzawa Y., Shimomura I. (2005) Visfatin: a protein secreted by visceral fat that mimics the effects of insulin. Science 307, 426-430; DOI 10.1126/science. 1097243

Gao Y., Wang C., Pan T., Luo L. (2014) Impact of metformin treatment and swimming exercise on visfatin levels in high-fat-induced obesity rats. Arq. Bras. Endocrinol. Metabol. 58, 42-47

Gentry L. R., Thompson Jr D. L., Gentry Jr G. T., Davis K. A., Godke R. A., Cartmill J. A. (2002) The relationship between body condition, leptin, and reproductive and hormonal characteristics of mares during the seasonal anovulatory period. J. Anim. Sci. 80, 2695-2703

Ghanbari-Niaki A., Saghebjoo M., Soltani R., Kirwan J. P. (2010) Plasma visfatin is increased after high-intensity exercise. Ann. Nutr. Metab. 57, 3-8; DOI 10.1159/000313936

Gordon M. E., McKeever K. H. (2005) Diurnal variation of ghrelin, leptin, and adiponectin in Standardbred mares. J. Anim. Sci. 83, 2365-2371; DOI 10.2527/2005.83102365x

Gordon M. E., McKeever K. H., Bokman S., Betros C. L., Manso-Filho H. C., Liburt N., Streltsova J. (2006) Interval exercise alters feed 
intake as well as leptin and ghrelin concentrations in Standardbred mares. Equine Vet. J. Suppl. 36, 596-605; DOI 10.1111/i.20423306.2006.tb05611.x

Haus J. M., Solomon T. P., Marchetti C. M., O'Leary V. B., Brooks L. M., Gonzalez F., Kirwan J. P. (2009) Decreased visfatin after exercise training correlates with improved glucose tolerance. Med. Sci. Sports Exerc. 41, 1255-1260; DOI 10.1249/MSS.0b013e 318195 bad5

Henneke D. R., Potter G. D., Kreider J. L., Yeates B. F. (1983) Relationship between condition score, physical measurements and body fat percentage in mares. Equine Vet. J. 15, 371-372

Jürimäe J., Gruodyte R., Saar M., Cicchella A., Stefanelli C., Passariello C., Maasalu K., Jürimäe T., von Duvillard S. P. (2011) Plasma visfatin and adiponectin concentrations in physically active adolescent girls: relationships with insulin sensitivity and body composition variables. J. Pediatr. Endocrinol. Metab. 24, 419-425

Jürimäe J., Rämson R., Mäestu J., Purge P., Jürimäe T., Arciero P. J., von Duvillard S. P. (2009) Plasma visfatin and ghrelin response to prolonged sculling in competitive male rowers. Med. Sci. Sports Exerc. 41, 137-143; DOI 10.1249/MSS.0b013e31818313e6

Kearns C. F., McKeever K. H., Roegner V., Brady S. M., Malinowski K. (2006) Adiponectin and leptin are related to fat mass in horses. Vet. J. 172, 460-465; DOI 10.1016/j.tvjl.2005.05.002

Kędzierski W. (2014) Changes in plasma leptin concentration during different types of exercise performed by horses. Animal 8, 14561461; DOI 10.1017/S1751731114001220

Kędzierski W. (2016a) Leptin fluctuations in trained horses, during a work season. J. Equine Vet. Sci. 43, 12-17; DOI 10.1016/i.jevs. 2016.04.094

Kędzierski W. (2016b) The effects of exercise on plasma leptin concentrations in horses. J. Equine Vet. Sci. 47, 36-41; DOI 10.1016/i.jevs.2016.08.003

Kędzierski W., Cywinska A. (2014) The effect of different physical exercise on plasma leptin, cortisol, and some energetic parameters concentrations in Purebred Arabian horses. J. Equine Vet. Sci. 34, 1059-1063; DOI 10.1016/i.jevs.2014.06.005

Kędzierski W., Kapica M. (2008) Plasma concentration of leptin and ghrelin in Standardbred foals as related to the age, sex, exercise and training. Animal 2, 582-587; 10.1017/S1751731 108001638

Lee K. J., Shin Y. A., Lee K. Y., Jun T. W., Song W. (2010) Aerobic exercise training-induced decrease in plasma visfatin and insulin resistance in obese female adolescents. Int. J. Sport Nutr. Exerc. Metab. 20, 275-281

MacLaren R., Cui W., Cianflone K. (2007) Visfatin expression is hormonally regulated by metabolic and sex hormones in 3T3-L1 preadipocytes and adipocytes. Diabetes Obes. Metab. 9, 490-497
Plinta R., Olszanecka-Glinianowicz M., Drosdzol-Cop A., Chudek J., Skrzypulec-Plinta V. (2012) The effect of three-month pre-season preparatory period and short-term exercise on plasma leptin, adiponectin, visfatin, and ghrelin levels in young female handball and basketball players. J. Endocrinol. Invest. 35, 595-601; DOI $10.3275 / 8014$

Ringmark S., Revold T., Jansson A. (2017) Effects of training distance on feed intake, growth, body condition and muscle glycogen content in young Standardbred horses fed a forage-only diet. Animal. 11, 1718-1726; DOI 10.1017/S1751731117000593

Roupas N. D., Mamali I., Armeni A. K., Markantes G. K., Theodoropoulou A., Alexandrides T. K., Leglise M., Markou K. B., Georgopoulos N. A. (2012) The influence of intensive physical training on salivary adipokine levels in Elite Thytmic Gymnasts. Horm. Metab. Res. 44, 980-986; DOI 10.1055/s-0032-1321816

Roupas N. D., Mamali I., Maragkos S., Leonidou L., Armeni A. K., Markantes G. K., Tsekouras A., Sakellaropoulos G. C., Markou K. B., Georgopoulos N. A. (2013) The effect of prolonged aerobic exercise on serum adipokine levels during an ultra-marathon endurance race. Hormones (Athens) 12, 275-282

Rudwill F., Blanc S., Gauquelin-Koch G., Choukèr A., Heer M., Simon C., Bergouignan A. (2013) Effects of different levels of physical inactivity on plasma visfatin in healthy normal-weight men. Appl. Physiol. Nutr. Metab. 38, 689-693; DOI 10.1139/apnm2012-0434

Seo D. I., So W. Y., Ha S., Yoo E. J., Kim D., Singh H., Fahs C. A., Rossow L., Bemben D. A., Bemben M. G., Kim E. (2011) Effects of 12 weeks of combined exercise training on visfatin and metabolic syndrome factors in obese middle-aged women. J. Sports Sci. Med. 10, 222-226

Suagee J. K., Corl B. A., Crisman M. V., Pleasant R. S., Thatcher C. D., Geor R. J. (2013) Relationships between body condition score and plasma inflammatory cytokines, insulin, and lipids in a mixed population of light-breed horses. J. Vet. Intern. Med. 27, 157 163; DOI 10.1111/jvim.12021

Szarska E., Cywi ska A., Ostaszewski P., Kowalska A. (2014) Effectiveness of training programmes used in two stables of thoroughbred race horses. Pol. J. Vet. Sci. 17, 681-685.

Wen Y., Wang H. W., Wu J., Lu H. L., Hu X. F., Cianflone K. (2006) Effects of fatty acid regulation on visfatin gene expression in adipocytes. Chin. Med. J. 119, 1701-1708

Wu X. T., Yang Z., Ansari A. R., Xiao K., Pang X. X., Luo Y., Song H. (2018) Visfatin regulates the production of lipopolysaccharideinduced inflammatory cytokines through p38 signaling in murine macrophages. Mikrobial Pathogenesis 117, 55-59; DOI 1016/j.micpath.2018.02.002 